\title{
A Hybrid Grey Wolf Optimizer and Artificial Bee Colony Algorithm Used for Improvement in Resource Allocation System for Cloud Technology
}

\author{
https://doi.org/10.3991/ijoe.v16i14.16623 \\ Soukaina Ouhame $\left({ }^{\bowtie}\right)$ Youssef Hadi \\ Ibn Tofail University, Kenitra, Morocco \\ soukaina.ouhame@uit.ac.ma \\ Arifullah \\ University Tun Hussein Onn Malaysia, Parit Raja, Malaysia
}

\begin{abstract}
Cloud computing is the next generation of technology which provide different service with the rule of pay and gain with the help of internet. These services consist of hardware and software used in different field of life. Due the growth of user in cloud environment the number of access and share system of technology increases which causes different issue and resource allocation system is one of them. In this paper for improvement in resource allocation system in VM a hybrid algorithm used because in some situation VM become underloaded and overloaded in cloud data center due to lack of proper load balancing technique system. Therefore, a hybrid technique used for improvement in VM allocation system. The hybrid technique consists of GWO and ABC algorithm three main section of GWO technique improve first improvement occur at local search section in this section $\mathrm{ABC}$ algorithm local search technique used second improvement occur at fitness function along with the energy parameter. The above proposed technique used to improve four main parameter of scheduling which are energy consumption, throughput network stability and average network executation time in resource allocation system in VM for cloud computing. The proposed technique result is compared with $\mathrm{ABC}$ algorithm, GWO algorithm, RAA algorithm based on those result the proposed algorithm improve $1.25 \%$ accuracy and efficiency for resource allocation system in VM for cloud computing.
\end{abstract}

Keywords - Cloud computing, resource allocation system, hybrid technique, load balancing, network executation

\section{$1 \quad$ Introduction}

Cloud computing growing day by day with rich feature and service it is also called as fifth generation of computing after mainframe, personal and client service. Now a day's different service is available in distributed manner. Last few years cloud computing has been grown very fast and many people and organization are moving toward 
placing their services on the cloud [1,2]. Cloud computing consists of different service like, communication, integrating, management, platform and network service, and different organization uses these services in different field according to their demand $[3,4]$.Cloud computing is growing rapidly and used every field of area like education, geospatial sciences, technologies, manufacturing, engineering, data intensive applications, health, life science, application programming services, different scientific, and business domains. Main advantage of cloud computing is, cost reduction, data security, scalability, mobility, disaster recovery, control and competitive edge due to these futures it become more reliable technology now a days. [5, 6]. Figure 1 show the structure of cloud computing.

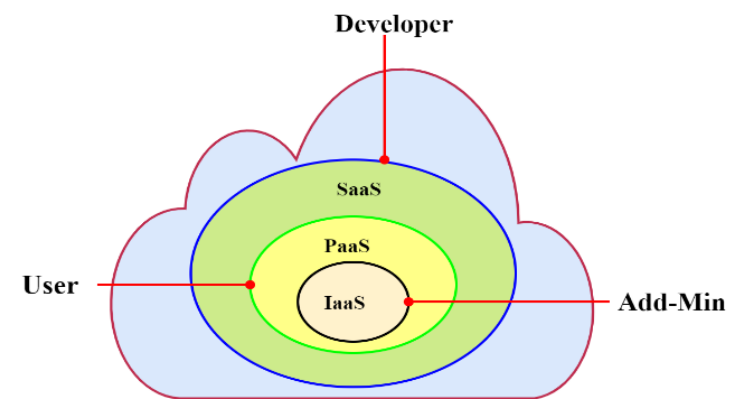

Fig. 1. Structure of cloud computing

There are many issues existing in cloud computing resource allocation is one them resource allocation is process in which different resource are distributed to different requirements along with proper rule which provide satisfaction for customer or developer [7]. For improvement in resource allocation for cloud computing different methods are used load balancing is one of them. Load balancing helps to distributed all load between all the viable node or VM. It relatively new technology and provide high resource utilization for better response time for different user demand [8,9]. Normally there are two main type of load balancing which are static load balancing and dynamic load balancing in distributed environment. Static load balancing is the type of load balancing which depends on the current state and its implementation also effect the current state, it not change able during the running of the program $[10,11]$. There are different types of static load balancing which can be implementing according to the requirement, one of the main disadvantages of this load balancing if one element falls then entire system down $[12,13]$. Dynamic load balancing is the process which can be change able at any stage and any location and no need previous knowledge. The main advantage of dynamic load balancing is that if any node fails its does not affect the entire system. It just affects the performance of network, different type of dynamic load balancing which can use according to their demand $[14,15]$. Cloud computing provide various services various data center are used to provide these services to the user in the whole world. Large numbers of virtual machine are used in data center there is change to unbalanced network due to the rapid growth. Resource allocation for cloud computing is important 
process for optimization technique a poor load balancing can make overloaded or underloaded VM while other remain idle [ 16,17].

\section{$2 \quad$ Related Work}

The author uses a hybrid technique of teaching -learning based optimization algorithm and grey wolf's optimization algorithm for resource allocation system in cloud computing for improvement of time, cost and avoidance of local optimum traps and this process reduce the amount of waiting time. Based on the result the proposed technique improves one parameter of cloud computing but still issue exit in load balancer section and network stability [18]. The author proposed multi-objective gray wolf optimization (LMOGWO) algorithm to solve the VM placement problems efficiently. This technique is used replace the retrieve true praetor front which activates the inactive VM the proposed technique improves the system energy consumption system. The proposed technique needs more improvement in resource allocation system [19]. The author proposes a hybrid algorithm combation of teaching-learning-based optimization (TLBO) and grey wolf's optimization algorithms (GWO) the purpose of hybrid is maximizing the throughput by improving in load balancing in VM these achievements was done due to the local search improvements. But still issue exit in global search in this technique due to which more energy consummation occurs [20]. The author proposed oppositional learning based grey wolf optimizer (OGWO) algorithm for parallel machine scheduling because due to parallel machine scheduling make issue for the entire system therefore this algorithm design for solve those issues. Based on the result the proposed technique improves the quality scheduling with less memory utilization and computation time. Even the good result the accuracy of system issue still exists in the network [21]. The author proposed a three-phase scheduling method by using by Grey Wolf Optimization (GWO) technique this technique used security level of optimized VMs, streamline security and introspection security analysis are exhausted for detecting the malware VMs which results the secured and efficient VMs for further resource allocation due to these change the result improve in security, time consummation and cost. Due to multiple architecture technique the network stability issue still exists in the system this is one of the big issues in this proposed technique [22]. Virtual machine is one of the important elements of cloud data center which are used to replace physical server. Now days due to the growth of technology different researcher trying to replace the VM therefore in this paper the author proposed enhanced levy based multi-objective gray wolf optimization (LMOGWO) algorithm for VM replacement. The proposed technique accuracy was check with different other well know technique and it result was better than other technique [23]. Cloud computing is the new paradigm which is used in different filed of life and resource allocation is one of the main issues in cloud computing. Therefore, the author proposed a technique including ant-lion optimizer (ALO) and Grey wolf optimizer (GWO) in task scheduling of the cloud computing environment based on the result the proposed technique improve the task allocation and network stability as compare Particle Swarm Optimization (PSO) and Firefly Algorithm (FFA) [24]. The author proposed technique for resource allocation which is known as an improved GWO 
(GWO) technique which focuses on the required meaningful balance between exploration and exploitation that leads to an optimal performance of the algorithm. Base on the result the proposed technique improves the effectiveness, efficiency, and stability as compare with the HS, ABC and PSO algorithms [25]. Resource allocation is important topic in cloud computing because with the help of this accuracy and efficiency improve in cloud computing. The author proposed modified Grey Wolf Optimizer (GWO) algorithm for resource allocation system in cloud computing. Each wolf updates its own position based on all the wolves selected before it. There is the possibility of finding solutions (hunts) quicker than according to other algorithms in the same category. The proposed algorithm improves the result as compare with another algorithm to compare with task allocation and network stability [26].

\section{Problems Statement}

Due to the rapid growth of cloud computing resource allocation in VM is one of main issue still exit. When user sent data to cloud data center sometime VM become underloaded or overloaded they make network failure or delay request therefore load balancing technique used to improve for resource allocation system. From the study of related work, it seen that GWO algorithm still issue in local search and fitness function for resource allocation system in VM. Therefore, this paper going to proposed hybrid technique for improvement in resource allocation for VM four main parameter are used to check the proposed technique performance which are network stability, make span, energy system and throughput.

\section{Proposed Techniques: Hybrid GWO with ABC}

Grey wolf optimization is Meta heuristic algorithm and derived from the hunting behaviour of the grey wolves and social hierarchy. The grey wolves have various groups for activities including hunting the prey. There are four main domain of grey wolves which are alpha $(\alpha)$ beta $(\beta)$ delta $(\delta)$ and omega $(\omega)$. The alpha wolfs are the leader of the group and it is in top of the grey wolf's hierarchy, which takes the decision about the hunting and food as well as controlling group activity. Whereas Beta are subordinate of aloha and support the decision made by the alpha and repents as candidate replace of alpha. Omega presents the next group or global group and its matins the group domain hierarchal structures the rest of the member of the group are classified as the subordinate to the omega. Figure 2 show the domain of GWO algorithm. Artificial bee algorithm proposed by Karaboga it was initially present for solving conations problems such as multi-variable and multi-modal continuous problems. The algorithm divided in to three main groups which are employed bees, onlookers, and scouts' bees. 


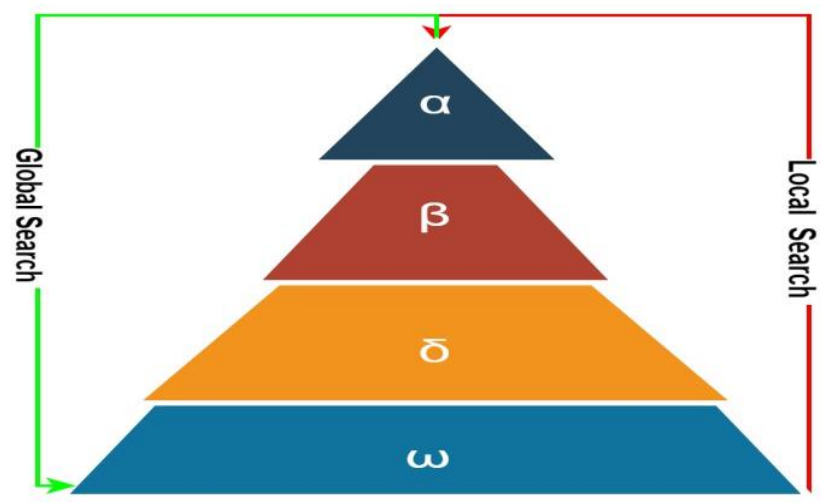

Fig. 2. Domain of GWO algorithm

The employed bee is the one who is currently performing exploitation on a food source. Figure 3 show the domain of ABC algorithm.

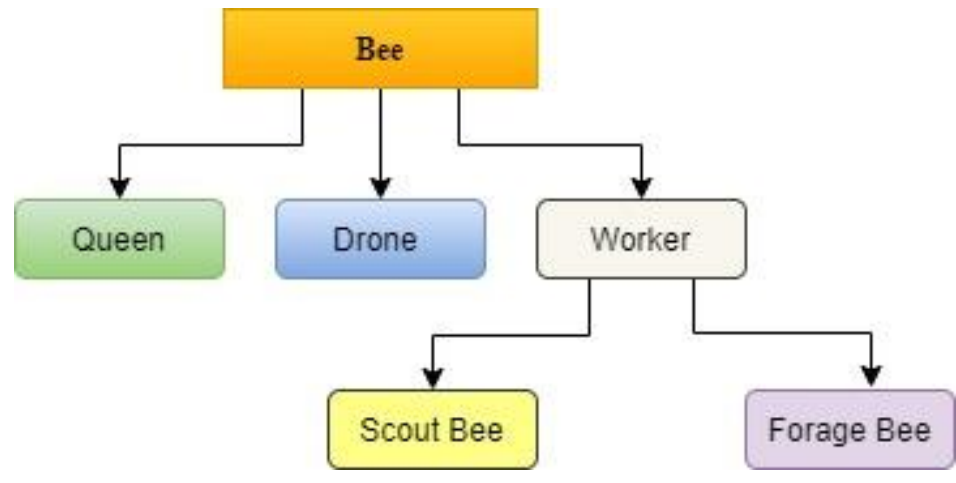

Fig. 3. Domain of $A B C$ algorithm

The general algorithmic structure of the $\mathrm{ABC}$ optimization approach is given as follows: Initialization phase repeat employed bees phase onlooker bees phase scout bees phase memorize the best solution achieved so far. The proposed hybrid algorithm is the combation of GWO and $\mathrm{ABC}$ algorithm these two algorithms are currently used as approximation for establishing resource allocation in VM based on makespan, network stability, energy and throughput. With such hybridization it is aimed at load balancing section of VM while maintaining the improvement at local search and increasing the efficiency whereas change at fitness function improve the accuracy of distribution of data to different VM properly. Figure 4 show the working of the propose technique. 


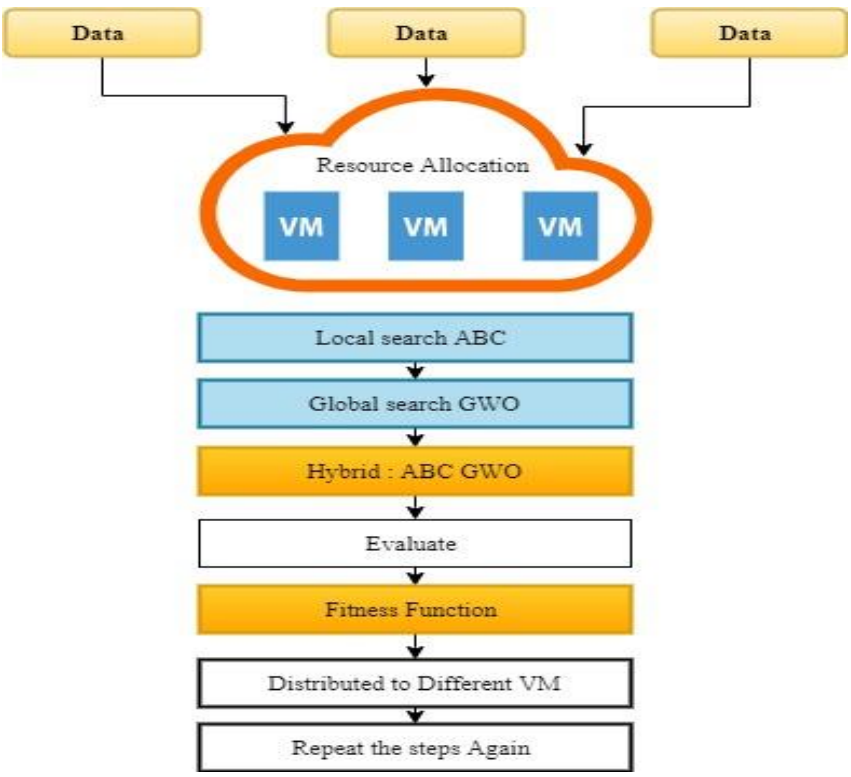

Fig. 4. Working of the propose technique

When tasks/data are arrives in the waiting queue of data center in cloud environment the representation of process can represent as.

$$
\begin{gathered}
\mathrm{UR}_{\mathrm{q}(\mathrm{x})=}[\mathrm{T} 1, \mathrm{~T} 2 \ldots \ldots \ldots \ldots \ldots \ldots . . \mathrm{Tn}] . \\
\mathrm{VM}(\mathrm{Dc})[\mathrm{VM} 1, \mathrm{VM} 2 \ldots \ldots \ldots \ldots . \mathrm{VMn}] .
\end{gathered}
$$

Where $\mathrm{UR}_{\mathrm{q}(\mathrm{x})}$ present the request or recving of data and $\mathrm{T} 1$...Tn presents different number of task or data. Where VM number of virtual machine and Dc in different data centre in cloud environment. From the initial population of ABC algorithm used random approach for local search let.

$\mathrm{Vi}=\left[\mathrm{VMi}_{(1)} \mathrm{VMi}_{(2) \ldots \ldots . . .} \mathrm{VMi}_{(\mathrm{n})}\right]$. Where ith represent the food source in the population and $\mathrm{n}$ is the number of destinations.

$$
\mathrm{VM}_{\mathrm{i}=}^{\mathrm{t}} \mathrm{VM}_{\min }^{\mathrm{t}}+\mathrm{R} \text { and }[0,1]\left(\mathrm{VM}_{\max }^{\mathrm{t}}-\mathrm{VM}_{\min }^{\mathrm{t}}\right)
$$

Where $\mathrm{VM}_{\text {max }}^{\mathrm{t}}$ and $\mathrm{VM}_{\text {min }}^{\mathrm{t}}$ are the lower and upper bound for the destination and $\mathrm{Ti}$ are task given.

Step 1: Local search for local search both employed bee and onlooker bee which are given below.

$$
\mathrm{VM}_{\text {new }}^{\mathrm{t}}=\mathrm{VM}_{\mathrm{j}}^{\mathrm{t}}+\text { Rand }[-1,1]\left(\mathrm{VM}_{\mathrm{j}}^{\mathrm{t}}-\mathrm{VM}_{\mathrm{k}}^{\mathrm{t}}\right)
$$

Where

$$
\mathrm{K} \varepsilon[1,2 \ldots \mathrm{SN}] \text {. }
$$

Step 2: From the second iteration the vectors $\vec{A}$ and $\vec{C}$ are calculated as. 


$$
\begin{gathered}
\overrightarrow{\mathrm{A}}=2 \overrightarrow{\mathrm{a}} \times \overrightarrow{\mathrm{r}}-\overrightarrow{\mathrm{a}} \\
\overrightarrow{\mathrm{c}}=2 \times \overrightarrow{\mathrm{r}} 2
\end{gathered}
$$

Where $\vec{a}$ linearly decreases from 2 to 0 over the course of interaction and $r 1, r 2$ are random vector when start second iteration the following position update to the solutions.

$$
\begin{gathered}
\overrightarrow{\mathrm{D}_{\sigma}}=\left[\overrightarrow{\mathrm{C}_{1}} * \overrightarrow{\mathrm{X}_{\sigma}}-\overrightarrow{\mathrm{X}}\right] \\
\overrightarrow{\mathrm{D}_{\mathrm{B}}}=\left[\overrightarrow{\mathrm{C}_{1}} * \overrightarrow{\mathrm{X}_{\mathrm{B}}}-\overrightarrow{\mathrm{X}}\right] \\
\overrightarrow{\mathrm{X}_{1}}=\overrightarrow{\mathrm{X}_{\alpha}}-\overrightarrow{\mathrm{A}_{1}} * \overrightarrow{\mathrm{D}_{\sigma}} \\
\overrightarrow{\mathrm{X}_{3}}=\overrightarrow{\mathrm{X}_{\alpha}}-\overrightarrow{\mathrm{A}_{3}} * \overrightarrow{\mathrm{D}_{\sigma}} \\
\overrightarrow{\mathrm{X}}(\mathrm{x}+1)=\left(\overrightarrow{\mathrm{X}_{1}}+\overrightarrow{\mathrm{X}_{2}}+\overrightarrow{\mathrm{X}_{3}}\right) / 3
\end{gathered}
$$

where the length(i) is the length of cloudlet (i) and Pei is the number of processing element (PE) request by cloudlet (i) MIPSj (millions of instruction per second) PEi is the number of $\mathrm{PE}$ in $\mathrm{VMj}$ and $\mathrm{n}$ is the number of $\mathrm{VMs}$ in a data center. Hence, we need to choose the solution schedule such that the $\mathrm{F}$ value is minimized.

$$
\vec{a}=2-\mathrm{t} \frac{2}{\text { Maxiter }}
$$

Where $\mathrm{t}=$ is the number of iteration and Maitre is the maximum number of iterations.

Step 3: After submitting data to the different VMj the current workload of all available VMs can be calculated by using the information that received from the data center. Thus, standard deviation (S.D) is called in order to measure the deviation of data on VMs standard deviation of data can be defined.

$$
\mathrm{SD}=\sqrt{\frac{1}{\mathrm{n}} \sum_{\mathrm{j}=0}^{\mathrm{n}}(\mathrm{Xj}-\mathrm{X}) 2}
$$

Processing time of data single by VM can be measured like

$$
\mathrm{X}_{\mathrm{j}}=\sum_{1}^{\mathrm{d}} \frac{\text { data-length (i) }}{\text { Capacity }}
$$

Means of processing time of all VMs for different data like

$$
\mathrm{X}_{\mathrm{j}}=\sum_{1}^{\mathrm{d}} \frac{\text { data-length (i) }}{\mathrm{n}-1}
$$

Where S.D is the standard deviation of load $n$ is number of all VMs is processing time of $\mathrm{VMj}$ which can be calculated based on (S.D) and $\mathrm{xj}$ is means processing time of $n$ virtual machine which calculated based on equation. If the value is equal to threshold value it means the VM is underloaded sent data if the value is less than the threshold value it means it overloaded not sent data to that VM. The steps are repeated until all data transmit to VMs. 


\section{$5 \quad$ Simulation Setup}

The proposed technique implemented using cloudsim 3.03 to check the four main parameter which are throughput, average network executation time, make span and energy consumption of cloud computing. The proposed Hybrid GWO with ABC algorithm result compare with $\mathrm{ABC}$ algorithm, RRA and GWO algorithm. After the simulation the result present in graphic form using origin software. Table 1 show the parameter which is used during simulation process.

Table 1. Experimental parameter used during simulation purpose

\begin{tabular}{|l|l|c|}
\hline \multicolumn{1}{|c|}{ Type } & \multicolumn{1}{|c|}{ Parameter } & Value \\
\hline Region & From 1 t0 5 & 5 \\
\hline Data Centre & Number of data centre & 5 \\
\hline & Number of hosts & Time and space \\
\hline & Type of Manager & 1000 \\
\hline Virtual machine & Bandwidth & $5 * 4=20$ \\
\hline & Total number of VM & 512 \\
\hline & Virtual machine memory & 1000 \\
\hline Task & VM image size & $500 / 600$ \\
\hline & Number of tasks & $150 \mathrm{~KB}$ \\
\hline & Length of task & Time and space \\
\hline Memory & Type of manager & $204800 \mathrm{Mb}$ \\
\hline & Total memory & 4 per VM \\
\hline
\end{tabular}

Table 1 shows the parameters according to this table the network has been established for simulation. Each simulation step two main parameter are change which are task number and user number to check the proposed technique performance.

\section{$6 \quad$ Result and Discussion}

This section presents the results which are taken from the simulation and compare with each other. Figure 5 show the throughput of 400 number of tasks and the total time of executation of the network which during process. 


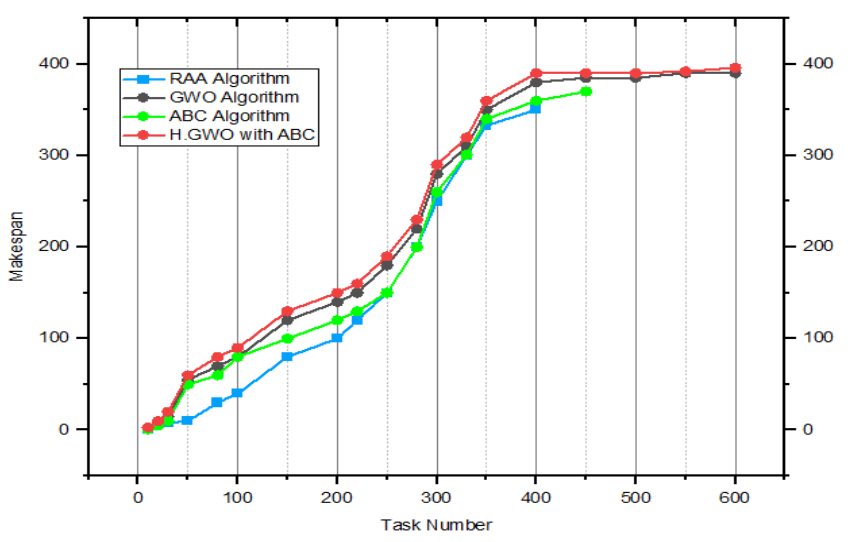

Fig. 5. Result of first simulation

Figure 6 compares the performance of throughput among all models. The number of VMs initialized as 20 number and 400 data or task given which are plated along $\mathrm{X}$-axis to check the make span plated in y-axis. The proposed model completes more number of task taking less time among all the modes. It means the proposed technique efficient take 360 second for 400 tasks during network execution. Figure 9 show the throughput of 400 number of task in the network.

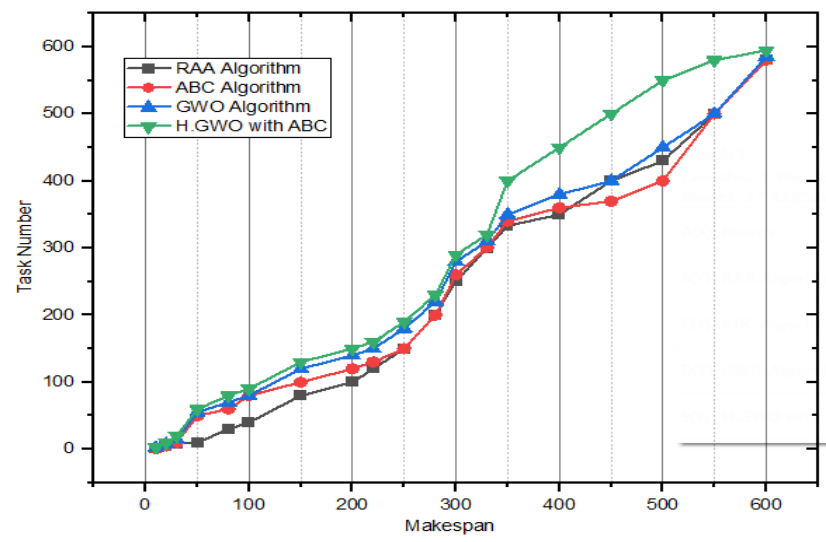

Fig. 6. Result of first simulation

Figure 6 compares the performance of throughput among all models. The number of VMs initialized as 30 number and 400 data or task given which are plated along y-axis to check the make span plated in $\mathrm{x}$-axis. The proposed model completes more number of throughputs 396 out of 400 tasks among all the modes. It means the proposed technique more efficient. Figure 7 show energy consumption of the network. 


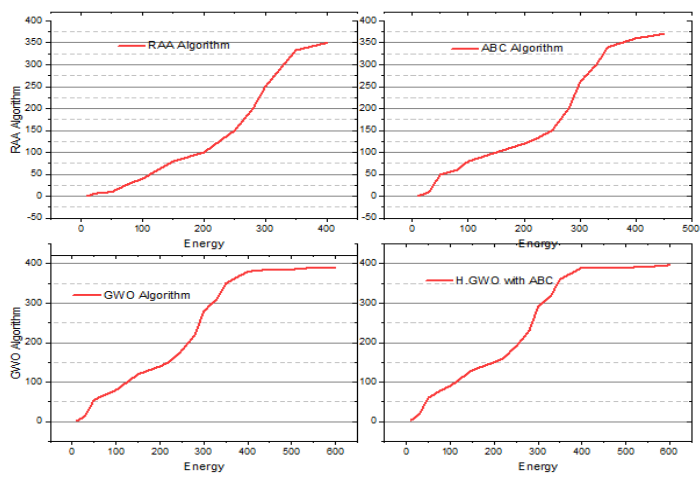

Fig. 7. Energy level of first simulation

Figure 7 show the performance of energy level of differ models based one the result the proposed models used less amount energy as compare to other models. Figure 9 show the network stability of 600 number of tasks in the network.

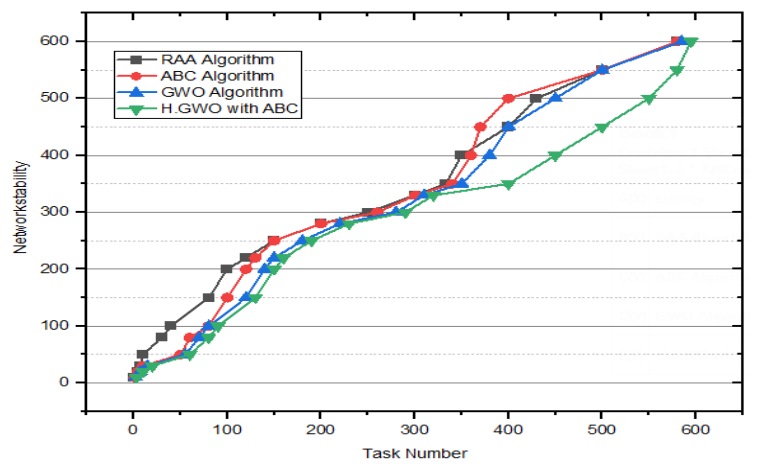

Fig. 8. Result of second simulation

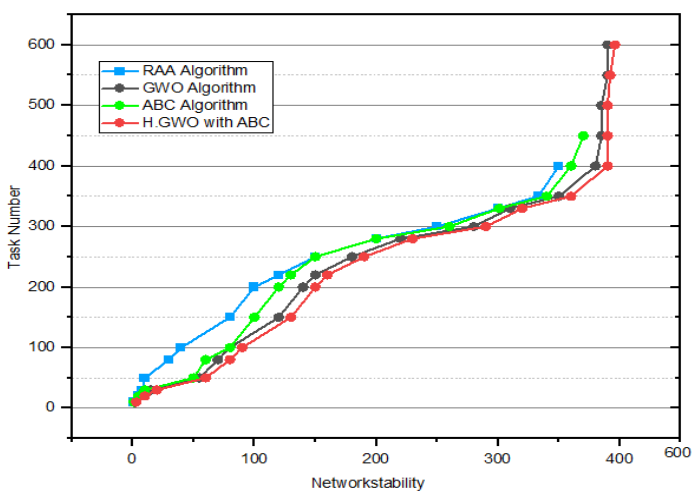

Fig. 9. Result of second simulation 
Figure 8 and figure 9 compares the performance of throughput among all models. The number of VMs initialized as 30 number and 600 data or task given which are plated along $\mathrm{x}$-axis to check the throughput while receive throughput is plated in $\mathrm{y}$-axis. The proposed model completes more number of tasks 594 out of 600 among all the modes. It means the proposed technique more efficient. Figure 10 and 11 show energy consumption of the network.

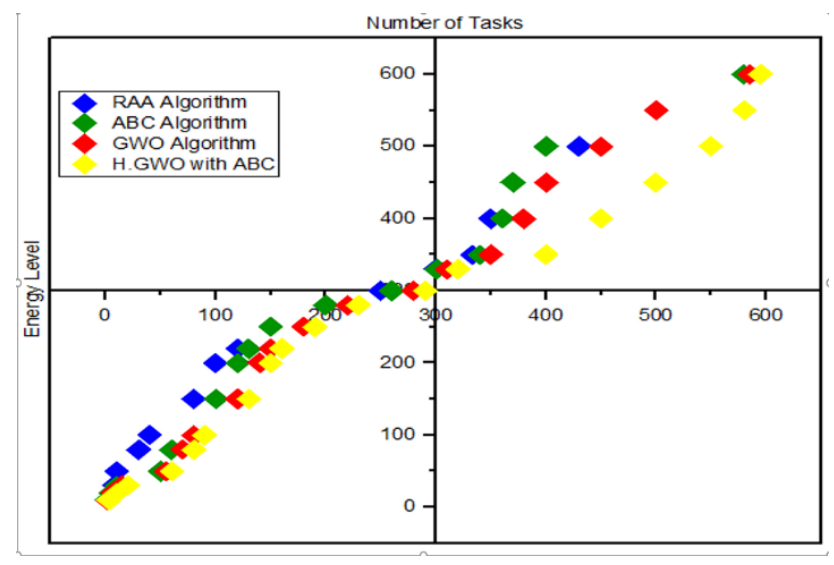

Fig. 10.Energy level of network

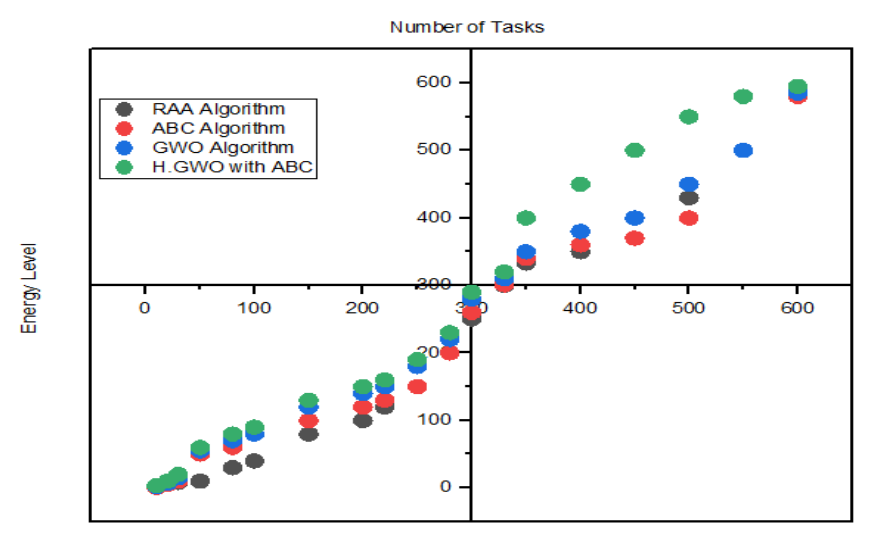

Fig. 11.Energy level of network

Figure 10 and 11 show the energy consumption of the network based of the total time executation of the network the proposed technique takes less amount energy it means the energy consumption 


\section{Conclusion}

For the improvement of scheduling in cloud computing in this study a new technique design which is known as Hybrid GWO with ABC algorithm. New technique design for improvement of four main parameter of scheduling which are throughput, energy consumption and average network executation time. Different numbers of task, different number of VM along with different number of users are used during executation of simulation. Based on those result the proposed technique is working more accurate in term of throughput, energy consumption and average network executation time in resource scheduling of VM for cloud commuting. Based on the result the proposed technique improves $1.25 \%$ in the four parameter of load balancing technique as compare to the other models in cloud computing.

\section{$8 \quad$ References}

[1] Umar, S., \& Baseer, S. (2016, August). Perception of cloud computing in universities of Peshawar, Pakistan. In 2016 Sixth International Conference on Innovative Computing Technology (INTECH) (pp. 87-91). IEEE. https://doi.org/10.1109/intech.2016.7845046

[2] Ullah, A., Nawi, N. M., Sutoyo, E., Shazad, A., Khan, S. N., \& Aamir, M. (2018). Search Engine Optimization Algorithms for Page Ranking: Comparative Study. International Journal of Integrated Engineering,10(6).

[3] Ullah, A., Nawi, N. M., Shahzad, A., Khan, S. N., \& Aamir, M. (2017). An e-learning system in Malaysia based on green computing and energy level. JOIV: International Journal on Informatics Visualization, 1(4-2), 184-187. https://doi.org/10.30630/joiv.1.4-2.63

[4] Ullah, A., \& Nawi, N. M. (2020). Enhancement to Dynamic Load Balancing Technique for Cloud Computing Using HBATAABC Algorithm. International Journal of Modeling, Simulation, and Scientific Computing. https://doi.org/10.1142/s1793962320500415

[5] Ullah, A. (2019). Artificial bee colony algorithm used for load balancing in cloud computing. IAES International Journal of Artificial Intelligence, 8(2), 156. https://doi.org/10. 11591/ijai.v8.i2.pp156-167

[6] Taha, H., \& Aknin, N. (2019). A Novel Model of Data Storage Service in the Architecture Cloud Storage. International Journal of Online and Biomedical Engineering (iJOE), 15(07), 66-83. https://doi.org/10.3991/ijoe.v15i07.10094

[7] Shahbazi, H., \& Jamshidi-Nejad, S. (2018, October). Smart deployment of virtual machines to reduce energy consumption of cloud computing-based data centers using gray wolf optimizer. In International Conference on Information and Software Technologies (pp. 164177). Springer, Cham. https://doi.org/10.1007/978-3-319-99972-2_13

[8] Rimal, B. P., Jukan, A., Katsaros, D., \& Goeleven, Y. (2011). Architectural requirements for cloud computing systems: an enterprise cloud approach. Journal of Grid Computing, 9(1), 3-26. https://doi.org/10.1007/s10723-010-9171-y

[9] Ren, Q. (2018). Massive Collaborative Wireless Sensor Network Structure Based on Cloud Computing. International Journal of Online and Biomedical Engineering (iJOE), 14(11), 415. https://doi.org/10.3991/ijoe.v14i11.9499

[10] Okagbue, H. I., Adamu, M. O., \& Anake, T. A. (2019). Differential evolution in wireless communications: A review. iJOE, 15(11), 29-51. https://doi.org/10.3991/ijoe.v15i11. $\underline{10651}$ 
[11] Natesan, G., and Chokkalingam, A. An improved grey wolf optimization algorithm-based task scheduling in cloud computing environment. Int. Arab J. Inf. Technol., No, 17(1), pp, 73-81, (2017). https://doi.org/10.34028/iajit/17/1/9

[12] Natesan, G., and Chokkalingam, A. Opposition learning-based grey wolf optimizer algorithm for parallel machine scheduling in cloud environment. International Journal of Intelligent Engineering and Systems, No 10(1), pp 186-195, (2017). https://doi.org/10.22266/ ijies2017.0228.20

[13] Natesan, G., \& Chokkalingam, A. (2020). An improved grey wolf optimization algorithmbased task scheduling in cloud computing environment. Int. Arab J. Inf. Technology. https://doi.org/10.34028/iajit/17/1/9

[14] Mousavi, S., Mosavi, A., Varkonyi-Koczy, A. R., and Fazekas, G. Dynamic resource allocation in cloud computing. Acta Polytechnica Hungarica, No 14(4), pp,83-104. (2017).

[15] Meraihi, Y., Ramdane-Cherif, A., Acheli, D., \& Mahseur, M. (2020). Dragonfly algorithm: a comprehensive review and applications. Neural Computing \& Applications. https://doi.org/10.1007/s00521-020-04866-y

[16] Ismaeel, S., Karim, R., \& Miri, A. (2018). Proactive dynamic virtual-machine consolidation for energy conservation in cloud data centres. Journal of Cloud Computing, 7(1), 10. https://doi.org/10.1186/s13677-018-0111-x

[17] Ismaeel, S., Al-Khazraji, A., \& Miri, A. (2019, April). An Efficient Workload Clustering Framework for Large-Scale Data Centers. In 2019 8th International Conference on Modeling Simulation and Applied Optimization (ICMSAO) (pp. 1-5). IEEE. https://doi.org/10. 1109/icmsao.2019.8880305

[18] Hatta, N. M., Zain, A. M., Sallehuddin, R., Shayfull, Z., \& Yusoff, Y. (2019). Recent studies on optimization method of Grey Wolf Optimiser (GWO): a review (2014-2017). Artificial Intelligence Review, 52(4), 2651-2683. https://doi.org/10.1007/s10462-018-9634-2

[19] Guzek, M., Bouvry, P., \& Talbi, E. G. (2015). A survey of evolutionary computation for resource management of processing in cloud computing. IEEE Computational Intelligence Magazine, 10(2), 53-67. https://doi.org/10.1109/mci.2015.2405351

[20] Fatima, A., Javaid, N., Anjum Butt, A., Sultana, T., Hussain, W., Bilal, M., ... and Ilahi, Man enhanced multi-objective gray wolf optimization for virtual machine placement in cloud data centres. Electronics, No 8(2), pp 218, (2019). https://doi.org/10.3390/electronics8020218

[21] Duan, L. M. (2018). Path Planning for Batch Picking of Warehousing and Logistics Robots Based on Modified A* Algorithm. International Journal of Online and Biomedical Engineering (iJOE), 14(11), 176-192. https://doi.org/10.3991/ijoe.v14i11.9527

[22] Celesti, A., Lay-Ekuakille, A., Wan, J., Fazio, M., Celesti, F., Romano, A., ... \& Villari, M. (2020). Information management in IoT cloud-based tele-rehabilitation as a service for smart cities: Comparison of NoSQL approaches. Measurement, 151, 107218. https://doi.org/10. 1016/j.measurement.2019.107218

[23] Aruna, M., Bhanu, D., \& Karthik, S. (2019). An improved load balanced metaheuristic scheduling in cloud. Cluster Computing, 22(5), 10873-10881. https://doi.org/10. 1007/s10586-017-1213-9

[24] Arivudainambi, D., and Dhanya, D. Resource allocation through optimized three-phase scheduled VMs by grey wolf optimization and introspection security analysis. Journal of Intelligent \& Fuzzy Systems, No,36(5), pp,4327-4340. (20190). https://doi.org/10. $\underline{3233 / \text { jifs- } 169989}$

[25] Al-Batah, M. S., Zaqaibeh, B. M., Alomari, S. A., \& Alzboon, M. S. (2019). Gene Microarray Cancer Classification using Correlation Based Feature Selection Algorithm and Rules Classifiers. International Journal of Online and Biomedical Engineering (iJOE), 15(08), 6273. https://doi.org/10.3991/ijoe.v15i08.10617 
[26] Akbar Neghabi, A., Jafari Navimipour, N., Hosseinzadeh, M., \& Rezaee, A. (2019). Natureinspired meta-heuristic algorithms for solving the load balancing problem in the softwaredefined network. International Journal of Communication Systems, 32(4), e3875. https://doi.org/10.1002/dac.3875

\section{Authors}

Soukaina Ouhame working as a scholar in Department of Computer Science from Ibn Tofail University, Kenitra, Morocco Email: soukaina.ouhame@uit.ac.ma

Youssef Hadi works as a professor in Department of Computer Science from Ibn Tofail University, Kenitra, Morocco. Email: hadi@uit.ac.ma

Arifullah is a PhD. Scholar at University Tun Hussein Onn Malaysia (UTHM). Arifullahms88@gmail.com

Article submitted 2020-06-26. Resubmitted 2020-07-28. Final acceptance 2020-07-30. Final version published as submitted by the authors. 